\title{
Simultaneous extraction, optimization, and analysis of flavonoids and polyphenols from peach and pumpkin extracts using a TLC-densitometric method
}

\author{
Ammar Altemimi ${ }^{1,2^{*}}$, Dennis G. Watson ${ }^{1}$, Mary Kinsel ${ }^{3}$ and David A. Lightfoot ${ }^{1}$
}

\begin{abstract}
Background: The use of medicinal plants has been reported throughout human history. In the fight against illnesses, medicinal plants represent the primary health care system for $60 \%$ of the world's population. Flavonoids are polyphenolic compounds with active anti-microbial properties; they are produced in plants as pigments. Quercetin, myricetin, and rutin are among the most well-known and prevalent flavonoids in plants, with an antioxidant activity capable of decreasing the oxidation of low density lipoproteins [LDLs]. To date, this research is the first of its kind to employ a coupled thin-layer chromatography (TLC) and a densitometric quantification method with a Box-Behnken design (BBD) response surface methodology (RSM) for optimization of ultrasonic-assisted extraction and determination of rutin and quercetin from peach and ellagic acid and myricetin from pumpkin fruits.
\end{abstract}

Results: The effect of process variables (extraction temperature $\left({ }^{\circ} \mathrm{C}\right)$, extraction power (\%) and extraction time (min)) on ultrasound-assisted extraction (UAE) were examined by using BBD and RSM. TLC followed by Quantity-One ${ }^{\text {TM }}$ (BioRad) image analysis as a simple and rapid method was used for identification and quantification of the compounds in complex mixtures. The results were consistent under optimal conditions among the experimental values and their predicted values. A mass spectrometry (MALDI-TOF MS) technique was also used to confirm the identity of the natural products in the TLC spots resolved.

Conclusion: The results show that the coupled TLC-densitometric methods \& BBD can be a very powerful approach to qualitative and quantitative analysis of; rutin and quercetin from peach extracts; and ellagic acid and myricetin contents from pumpkin extracts.

Keywords: Ellagic acid, Rutin, Myricetin, Ultrasound, TLC, Densitometry, Mass spectrometry

\section{Introduction}

The use of medicinal plants has been reported throughout human history [1]. In the fight against illnesses, medicinal plants represent the primary health care system for $60 \%$ of the world's population. With the advent of chemistry, modern pharmacotherapy has depended more on synthetic drugs, however due to raised safety concerns and lower drug efficiency there is a growing interest to show

\footnotetext{
* Correspondence: ammaragr@siu.edu

${ }^{1}$ Department of Plant, Soil and Agricultural Systems, Southern Illinois

University, Carbondale, IL 62901, USA

²Department of Food Science, College of Agriculture, University of Basrah,

Basrah 61004, Iraq

Full list of author information is available at the end of the article
}

direct evidence of the crucial role of natural secondary metabolites [2-4].

Flavonoids are polyphenolic compounds with active phytoalexins (anti-microbial) properties; they are produced in plants as pigments [5]. Quercetin, myricetin, and rutin are among the most well-known and prevalent flavonoids in plants, with an antioxidant activity capable of decreasing low density lipoproteins [LDL] oxidation [6]. Different types of hydro-alcoholic mixtures have been used to extract flavonoid from the plant material $[7,8]$. Methanol or ethanol was employed depending on the targeted compounds [9]. Extraction techniques for flavonoids are typically called traditional and modern 
methods [10]. Maceration, reflux, percolation, and Soxhlet extraction are within the lists of traditional methods, which have been significantly improved by automation [11]. Currently the focus has been on modern methods that were developed to be more efficient, faster, and with lower consumption of organic solvent $[10,12,13]$. Some of the modern methods are ultrasound assisted extraction (UAE), microwave assisted extraction (MAE), pressurized liquid extraction (PLE), and supercritical fluid extraction (SFE) $[14,15]$.

Many methods have been used to isolate and measure the activity of antioxidant compounds [16]. Recently, thin layer chromatography (TLC) analysis of flavonoids in plant and animal samples was used for studying the application of scanning densitometry in quantification of flavonoids [17]. TLC is widely used because it is relatively simple, rapid, inexpensive, and accurate method for chemical identification when coupled with mass spectrometry (MS) [18]. TLC combined with densitometry and image analysis can have the ability to measure medicinal plant components [19]. Densitometry can be used to measure the differences among absorbance or fluorescence signals between a separated zone and the empty plate background across a range of wavelengths [20]. Image analysis methods are used to compare the spot color intensity with the plate color background. The peak area of the test spots are compared with data from calibration standards chromatographed on the same plate [21, 22].

Several techniques have been used in the past for determining plant extracts, including TLC [23]; GC-MS [24]; and HPLC [25]. There are no known reports that described a coupled TLC-densitometry method for quantitative determination of; ellagic acid and myricetin from pumpkin; or quercetin and rutin from peach. This study employed a coupled TLC densitometric method and Box-Behnken design (BBD) with response surface methodology (RSM) for optimization of UAE. Isolated products identities were confirmed by using matrix-assisted laser desorption/ionization time-off-light MS (MALDI-TOF MS) analysis.

\section{Experimental}

\section{Plant material}

All crops were grown on bare soil, a silt loam typical of southern Illinois. Fresh peaches (Red Haven) and pumpkins (Libbys Select) were harvested from several plants selected at random within a field at the Horticulture Research Center farm on Rowden Road near Southern Illinois University (Carbondale, IL). Peaches and pumpkins were grown according to conventional commercial methods for southern Illinois. Synthetic nutrients and pesticides were applied according to recommendations for peach and pumpkin production in southern Illinois.
The samples were provided by Dr. Alan Walter (Department of Plant, Soil and Agricultural Systems, College of Agricultural Sciences, Southern Illinois University, USA). The fruits were cleaned and sliced into small pieces and crushed in a blender, and then sealed and stored in plastic bags in home refrigerator $\left(-18{ }^{\circ} \mathrm{C}\right)$ for five days before freeze-drying.

\section{Ultrasonic assisted extraction (UAE)}

An Elmasonic P30 (P30) ultrasonic device with heated water bath (Elma Hans Schmidbauer GMBH, Singen, Germany) set at $37 \mathrm{kHz}$ was used for this study. User adjustable controls were heated bath temperature and power setting as a percentage of full power (30-100 \%). The standard ultrasonic mode was used. The manufacturer rated the P30 with an effective power rating of $120 \mathrm{~W}$. The P30 had a proprietary algorithm to adjust power based on the impedance of the system, resulting in the effective power rating. For a specific power setting, samples experienced the same degree of cavitation regardless of the load in the tank. For all treatments, the bath of the P30 contained $1.7 \mathrm{~L}$ of water before the treatment containers were added. Ultrasonic power was expressed as $\mathrm{W} / \mathrm{cm}^{2}$, based on the power setting as a percentage of rated power and the volume of the bath solution.

Although numerous variables my affect a process, identifying and controlling each variable with small contributions is practically impossible, therefore, variables were selected with known major effects [26]. The prior work of Altemimi et al. [27, 28] with the same ultrasonic equipment was used as a guide and selected variables were bath temperatures of $30{ }^{\circ} \mathrm{C}, 40{ }^{\circ} \mathrm{C}$, and $50{ }^{\circ} \mathrm{C}$; power level settings of $30 \%, 50 \%$, and $70 \%$; and ultrasonic duration of $10 \mathrm{~min}, 20 \mathrm{~min}$, and $30 \mathrm{~min}$. The ultrasonic bath temperature was controlled by coupling with a cooling system using a cooling coil (Fisher Scientific Inc. St Louis USA) and water pump (model HJ-111, submersible pump, flow rate $250 \mathrm{~L} / \mathrm{h}$, Sunsun Inc., Zhejiang, China). Coupled heating and cooling helped to maintain temperatures that were evenly distributed across the ultrasonic water bath. Based on the manufacturer's effective power rating, the ultrasonic power for the three power settings inside the extract containers was $21 \mathrm{~W} / \mathrm{cm}^{2}$, $35 \mathrm{~W} / \mathrm{cm}^{2}$, and $49 \mathrm{~W} / \mathrm{cm}^{2}$, respectively. A calorimetric method was used to independently verify the power settings [29].

Ten grams of the lyophilized samples were weighed and $100 \mathrm{~mL}$ of methanol were added to the samples in a $200 \mathrm{~mL}$ glass flask. Each flask was placed in the P30 and treated. After the samples had been exposed to ultrasound waves, the upper layer was filtered (Whatman no. 1) and placed in a rotary evaporator under vacuum at $40{ }^{\circ} \mathrm{C}$ to remove solvent. 


\section{Experimental design}

The effects of three independent variables of temperature, power, and time to optimize the extracted amount of compounds were investigated by using a BBD for RSM. The coded values of the experimental factors and settings for the experimental design were summarized in Table 1. The 17 ultrasonic treatments were completed in random order. The experimental data were analyzed with multiple regressions to fit the quadratic polynomial model in Eq. 1.

$$
Y=b_{0} \sum_{\mathrm{i}=1}^{3} b_{\mathrm{i}} X_{\mathrm{i}}+\sum_{\mathrm{i}=1}^{3} b_{\mathrm{ii}} X_{\mathrm{i}}^{2}+\sum_{\mathrm{i} \neq j=1}^{3} b_{\mathrm{ii}} X_{\mathrm{i}} X_{j}
$$

Where $\mathrm{Y}$ is the predicted response; $\mathrm{b}_{0}$ is the intercept; $b_{1}, b_{2}$ and $b_{3}$ are the linear coefficients of temperature $\left(\mathrm{X}_{1}\right)$, power $\left(X_{2}\right)$ and time $\left(\mathrm{X}_{3}\right)$, respectively; $\mathrm{b}_{11}, \mathrm{~b}_{22}$ and $b_{33}$ are the squared coefficient of temperature of sonication, power and time, respectively; $b_{12}, b_{13}$ and $b_{23}$ are the interaction coefficients of temperature of sonication, power and time, respectively. The settings of the independent variables were represented as $X_{i}$ to $X_{j}$.

\section{Thin layer chromatography chemical screening}

The glass TLC plates were $20 \mathrm{~cm}$ by $20 \mathrm{~cm}$ and pre-coated with silica gel 60 F254 (E. Merck/Millipore, Billerica, MA) (0.2 mm thickness). The following solvents were screened to determine the best separation compound for the TLC technique: 1) ethyl acetate 5: acetone $4(\mathrm{v} / \mathrm{v}), 2)$ hexane 10: chloroform $10(\mathrm{v} / \mathrm{v})$, and 3) ethyl acetate10: formic acid 2: water $3(\mathrm{v} / \mathrm{v})$. The TLC plate was placed into oven at $110{ }^{\circ} \mathrm{C}$ for $20-30 \mathrm{~min}$ to be completely dried. Each of the solvents was evaluated by mixing and placing $100 \mathrm{~mL}$ into a rectangular chromatography glass tank with ground edges. The glass tank was covered with a glass lid and solvents were allowed to saturate for 30-40 min before use. Two $\mu \mathrm{L}$ of each crude extract were added by syringe to a different TLC plate. The crude extracts were placed in a drop shape for identification and spread of the separated compounds according to Harbone [30]. Flavonoids have a weak natural fluorescence characterization and must be enhanced during separation on chromatography plates. The flavonoids fluorescence was enhanced by spraying the TLC plates with different complex agents. The most common complex agent used to increase the flavonoids fluorescence was the diphenyl-boric acid 2-amino ethyl ester (DPBA) [31]. Images of the TLC plates were analyzed using Quantity One ${ }^{\mathrm{Tw}}$ densitometry software (Bio-Rad, Hercules, CA). The compounds in the samples were quantified by comparing density of the peaks and their areas (expressed as intensity per $\mathrm{mm}^{2}$ ) from the samples with those from standard solutions of rutin, qurecetin, ellagic acid, and myricetin on the same plate. The best separation was obtained by ethyl acetate10: formic acid 2: water $3(\mathrm{v} / \mathrm{v})$ [32]. The software evaluated the area of separated spots by comparing the spot color intensity to the color of the TLC plate background. It was essential to chromatograph

Table 1 Combinations of temperature, power and time with their coded level terms in parentheses terms obtained from RSM ${ }^{a}$ and the observed values of rutin, quercetin, ellagic acid, and myricetin

\begin{tabular}{|c|c|c|c|c|c|c|c|}
\hline Run & Factor 1: A temperature ${ }^{\circ} \mathrm{C}$ & Factor 2: B power \% & Factor 3: C time min & Rutin $\mu \mathrm{g} / \mathrm{g}$ & Quercetin $\mu \mathrm{g} / \mathrm{g}$ & Ellagic acid $\mu \mathrm{g} / \mathrm{g}$ & Myricetin $\mu \mathrm{g} / \mathrm{g}$ \\
\hline 1 & $40(0)$ & $30(-1)$ & $10(-1)$ & 2.65 & 2.54 & 3 & 2.96 \\
\hline 2 & $50(1)$ & $50(0)$ & $10(-1)$ & 2.56 & 2.44 & 2.88 & 2.84 \\
\hline 3 & $40(0)$ & $70(1)$ & $10(-1)$ & 2.67 & 2.55 & 2.98 & 2.94 \\
\hline 4 & $30(-1)$ & $50(0)$ & $30(1)$ & 2.72 & 2.6 & 2.69 & 2.65 \\
\hline 5 & $40(0)$ & $50(0)$ & $20(0)$ & 2.90 & 2.8 & 2.99 & 2.95 \\
\hline 6 & $40(0)$ & $70(1)$ & $30(1)$ & 2.79 & 2.66 & 2.83 & 2.79 \\
\hline 7 & $50(1)$ & $50(0)$ & $30(1)$ & 2.75 & 2.63 & 2.89 & 2.85 \\
\hline 8 & $30(-1)$ & $30(-1)$ & $20(0)$ & 2.57 & 2.45 & 2.93 & 2.89 \\
\hline 9 & $40(0)$ & $50(0)$ & $20(0)$ & 2.89 & 2.77 & 3.03 & 2.98 \\
\hline 10 & $50(1)$ & $70(1)$ & $20(0)$ & 2.72 & 2.6 & 2.98 & 2.94 \\
\hline 11 & $30(-1)$ & $50(0)$ & $10(-1)$ & 2.54 & 2.42 & 2.85 & 2.81 \\
\hline 12 & $30(-1)$ & $70(1)$ & $20(0)$ & 2.62 & 2.5 & 2.79 & 2.75 \\
\hline 13 & $40(0)$ & $50(0)$ & $20(0)$ & 2.89 & 2.78 & 3.02 & 2.97 \\
\hline 14 & $50(1)$ & $30(-1)$ & $20(0)$ & 2.68 & 2.56 & 2.88 & 2.84 \\
\hline 15 & $40(0)$ & $50(0)$ & $20(0)$ & 2.88 & 2.76 & 2.95 & 2.91 \\
\hline 16 & $40(0)$ & $30(-1)$ & $30(1)$ & 2.71 & 2.59 & 2.95 & 2.91 \\
\hline 17 & $40(0)$ & $50(0)$ & $20(0)$ & 2.85 & 2.73 & 3.02 & 2.95 \\
\hline
\end{tabular}

${ }^{a}$ The results were obtained with the Design Expert 9.0 software 
the standards on the same plates to compensate for slight variations among the different plates (Figs. 1 and 2). The software generated a final chromatogram image that allowed the quantitative evaluation of the TLC separation by densitometry.

\section{Preparation of calibration curves for rutin and quercetin from peach extracts and ellagic acid and myricetin frompumpkin extracts}

All chemicals used in the experiments were analytical grade reference standard compounds. Rutin (R) (purity $98 \%$ ) was procured from Indofine Chemical Company (Hillsborough Township, NJ, USA) and quercetin (Q) (purity $99.32 \%$ ) was purchased from MP Biomedicals LLC (Santa Ana, CA, USA). ellagic acid (E) (purity $99 \%$ ) was procured from MP Biomedicals LLC (Santa Ana, CA, USA), and myricetin (M) (purity $98 \%$ ) was purchased from Alfa Aesar, MA, USA. The stock solution of rutin $\left(70 \mu \mathrm{g} . \mu \mathrm{L}^{-1}\right)$ was prepared in methanol. Different volumes of stock solution $2,4,6,8,10$, and $12 \mu \mathrm{L}$, were spotted on the TLC plate to obtain concentrations of $140,280,420,560,700$, and $840 \mu \mathrm{g} \mathrm{spot}^{-1}$ of rutin, respectively. The stock solution of quercetin $(80 \mu \mathrm{g} . \mu \mathrm{L}$ ${ }^{-1}$ ) was prepared in methanol. Different volumes of the stock solution $2,4,6,8,10$, and $12 \mu \mathrm{L}$, were spotted on the TLC plate to obtain concentrations of 160,320 , $480,690,800$, and $960 \mu \mathrm{g} \mathrm{spot}^{-1}$ of quercetin, respectively. Different volumes of stock solution 2, 4, 6, 8, 10, and $12 \mu \mathrm{L}$, were spotted on the TLC plate to obtain concentrations of $150,300,450,600,750$, and $900 \mu \mathrm{g}$ spot $^{-1}$ of ellagic acid, respectively. The stock solution of myricetin $\left(70 \mu \mathrm{g} . \mu \mathrm{L}^{-1}\right)$ was prepared in methanol. Different volumes of the stock solution $2,4,6,8,10$, and $12 \mu \mathrm{L}$, were spotted on the TLC plate to obtain concentrations of $140,280,420,560,700$, and $840 \mu \mathrm{g}$ spot $^{-1}$ of myricetin, respectively. These spots of the reference compounds were used to determine the calibration curves for the TLC-densitometry. The calibration curves were used by Quantity One ${ }^{\mathrm{TM}}$ software to generate accurate quantification of rutin, quercetin, ellagic acid, and myricetin in the experimental samples.
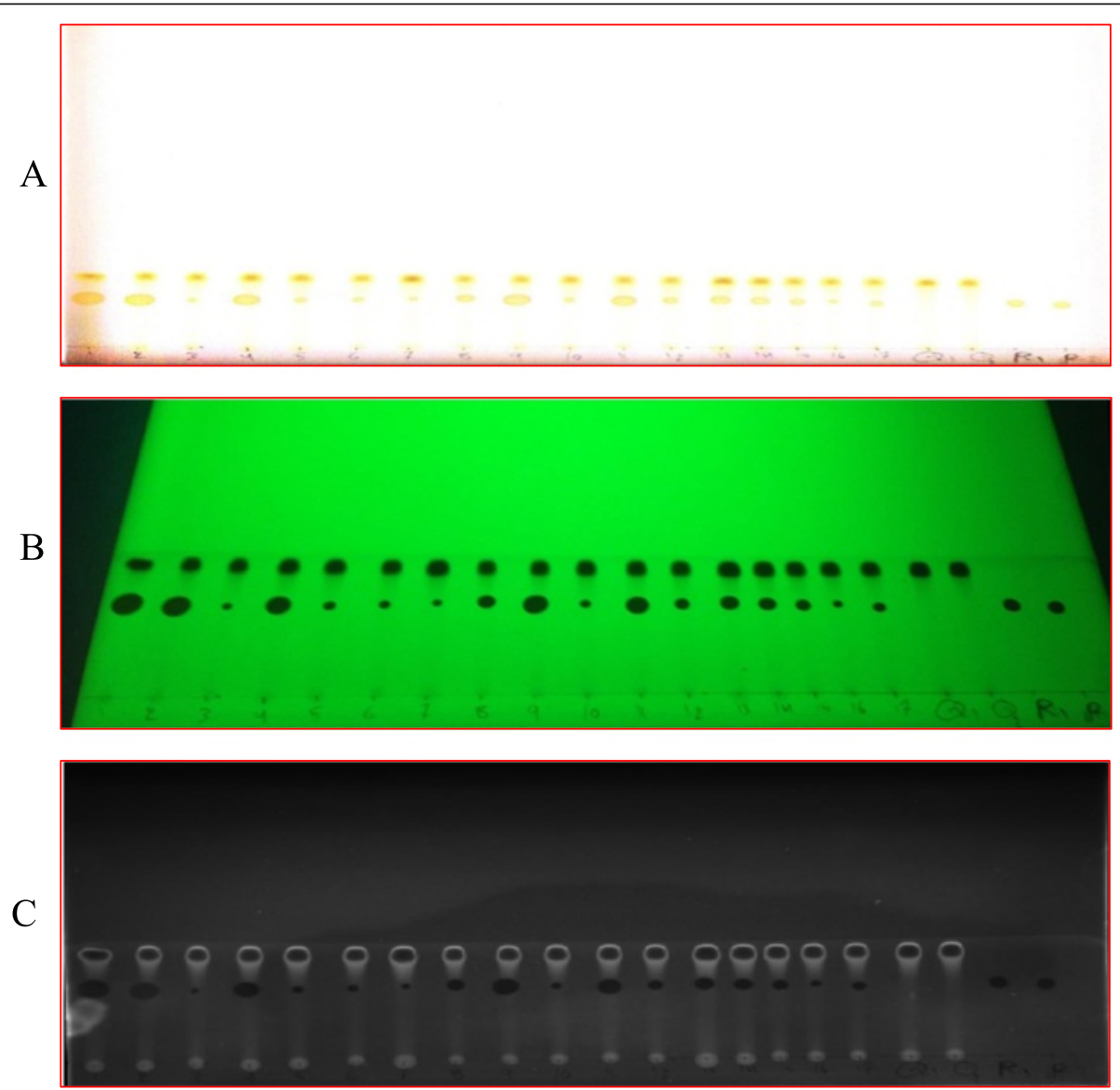

Fig. 1 The chromatographic separation of quercetin (Q) and Rutin (R): (a) real image; (b) UV image at at $254 \mathrm{~nm}$; and (c) grey scale image quantity one software. Spots: 1 to 17 for samples extracts 

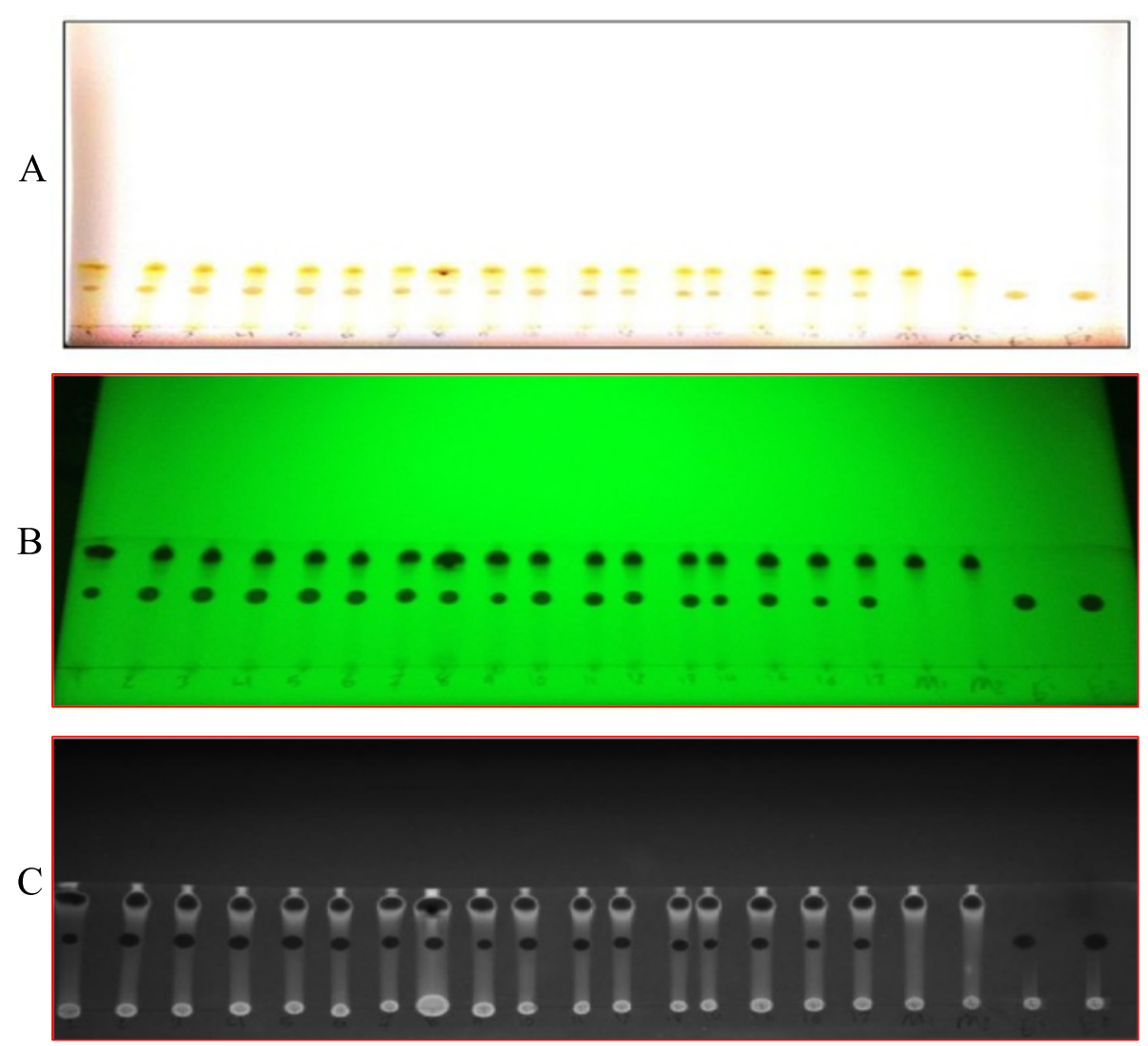

Fig. 2 The chromatographic separation of myricetin (M) and ellagic acid (E): (a) real image; (b) UV image at at $254 \mathrm{~nm}$; and (c) grey scale image by quantity one software. Spots: 1 to 17 for samples extracts

Simultaneous quantification of rutin and quercetin from peach extracts and ellagic acid and myricetin from pumpkin extracts

Two $\mu \mathrm{L}$ of each of the 17 plants extracts were applied on a TLC plate. The plate was developed and scanned as described in the TLC chemical screening process. The peak areas were recorded and the amounts of rutin and quercetin from peach extracts and ellagic acid and myricetin from pumpkin extracts were calculated using the respective calibration curves.

\section{Diagnostic checking of RSM model and validity testing}

Design-Expert ${ }^{\mathrm{TM}}$ software (version 9) was used to analyze the experimental results of the response surface design (State-Ease lnc. Minneapolis, MN, USA). P-values less than 0.05 were used to determine statistical significance of differences. Independent variables of extraction temperature, ultrasonic power, and extraction time were simultaneously optimized using RSM. Subsequently the output for each isolated compound was measured from peach and pumpkin extracts under the optimum ultrasonic conditions. The ultrasonic experiments using the optimum conditions were replicated three times and the results were compared with the predicted values for validation of the model.

\section{Mass spectrometric analysis}

The confirmation of each TLC spot identity was achieved using time-of-flight mass spectrometry. Each TLC spot of interest was excised and the compound was extracted into methanol. The freshly extracted compounds were then prepared for either matrix - assisted laser desorption ionization (MALDI) or laser desorption ionization (LDI). Certified standards of quercetin, rutin, ellagic acid, and myricetin were analyzed in tandem to confirm the identity of each compound.

A $1-\mu L$ aliquot of TLC Spot Q, R, and M methanol extracts were spotted separately with $1-\mu \mathrm{L}$ of a MALDI matrix solution of $\alpha$ - cyano-4-hydroxycinnamic acid $(\alpha \mathrm{CHCA}, 5 \mathrm{mg} / \mathrm{mL} \alpha \mathrm{CHCA}$ in 50:50 (v:v) acetonitrile: $0.1 \%(\mathrm{v} / \mathrm{v})$ trifluoroacetic acid in water). A $1 \mu \mathrm{L}$ aliquot of TLC Spot E methanol extract was also spotted on the stainless steel sample plate with no MALDI matrix. The TLC Spots Q, R, M, and E were allowed to dry at room temperature. The stainless steel sample plate containing the dried MALDI and LDI samples was inserted into Bruker Daltonics (Billerica, MA, USA) MicroFlexLR time- 
of-flight mass spectrometer. The samples were irradiated with a pulsed nitrogen laser and the positive ion signal was recorded in the mass-to-charge $(\mathrm{m} / \mathrm{z})$ region of 20 to 1000. Each mass spectrum consisted of an average of 1000 laser shots.

\section{Results and discussion}

Chromatographic separation and image analysis software TLC-densitometry coupled with image analysis detection was evaluated for the quantitative determination of induced flavonoids. According to the Figs. 1 and 2, the images allowed a visual evaluation of the flavonoids and polyphenolic acids (yellow-orange fluorescence) [33]. The method was suitable for rapid quantification of rutin and qurecetin in peach extracts and ellagic acid and myricetin in pumpkin extracts. It required less time for sample preparation and quantification compared to HPLC. These findings were in reasonable agreement with Nikolova et al. [22] and Naşcu-Briciu et al. [10] who found that TLC- densitometric analysis with image analysis software was complementary to the photodensitometric methods.

\section{Fitting the models}

The preliminary experiments were very advantageous in order to screen and choose the levels of independent variables for peach and pumpkin extracts. The experimental design for Box-Behnken and corresponding response data are presented in Table 1. According to the results in Table 1, the quadratic polynomial model was assigned for multiple regression analysis. The contribution of the quadratic model within regression coefficients analysis and the analysis of variance (ANOVA) are shown in Tables 2 and 3 [34]. In general, the variation in the data around the fitted model was examined using lack of fit test for the model [35]. Lack of fit must not be significant $(p>0.05)$ for an appropriate model.

\section{Effect of ultrasonic parameters on rutin and quercetin contents of peach and analysis of response surfaces} ANOVA analysis and regression coefficients (Table 2) were obtained in order to test the fitted quadratic surface models for rutin and quercetin content in peach extracts. For rutin content ( $\mu \mathrm{g} / \mathrm{g}$ of dry matter), the linear parameter (time) was significant and interaction parameters (temp*power, temp* time, time*power) were not significant $(p>0.05)$, whereas all quadratic parameters were significant $(p<0.05)$. In quercetin content $(\mu \mathrm{g} / \mathrm{g}$ of dry matter), the interaction parameter (time* power) was significant at the level of $p<0.001$ and the parameters (temp*power, temp"time) were not significant $(p>0.05)$ while all quadratic parameters were
Table 2 Analysis of variance results for the regression (peach)

\begin{tabular}{|c|c|c|c|c|c|}
\hline Source & $\begin{array}{l}\text { Degree of } \\
\text { freedom }\end{array}$ & $\begin{array}{l}\text { Sum of } \\
\text { square }\end{array}$ & $\begin{array}{l}\text { Mean } \\
\text { square }\end{array}$ & F-value & $p$-value \\
\hline \multicolumn{6}{|l|}{ Rutin } \\
\hline Model & 9 & 0.2400 & 0.027 & 17.41 & 0.0005 \\
\hline$x_{1}$ & 1 & 0.0084 & 0.0084 & 5.52 & 0.0512 \\
\hline$x_{2}$ & 1 & 0.0045 & 0.0045 & 2.95 & 0.1298 \\
\hline$x_{3}$ & 1 & 0.0378 & 0.0378 & 24.68 & 0.0016 \\
\hline$x_{1} x_{2}$ & 1 & 2.500 & 2.500 & 0.016 & 0.9019 \\
\hline$x_{1} x_{3}$ & 1 & 2.500 & 2.500 & 0.016 & 0.9019 \\
\hline$x_{2} x_{3}$ & 1 & 0.0009 & 0.0009 & 0.59 & 0.4685 \\
\hline$x_{1}^{2}$ & 1 & 0.0979 & 0.0979 & 63.91 & $<0.0001$ \\
\hline$x_{2}^{2}$ & 1 & 0.0341 & 0.0341 & 22.26 & 0.0022 \\
\hline$x_{3}^{2}$ & 1 & 0.038 & 0.038 & 24.80 & 0.0016 \\
\hline Lack of fit & 3 & 0.007725 & 0.002575 & 3.43 & 0.1322 \\
\hline \multicolumn{6}{|l|}{ Quercetin } \\
\hline Model & 9 & 0.2336 & 0.026 & 12.86 & 0.0014 \\
\hline$x_{1}$ & 1 & 0.0024 & 0.0024 & 1.21 & 0.3070 \\
\hline$x_{2}$ & 1 & 0.0097 & 0.0097 & 4.85 & 0.0634 \\
\hline$x_{3}$ & 1 & 0.0024 & 0.0024 & 1.21 & 0.3070 \\
\hline$x_{1} x_{2}$ & 1 & 0.0006 & 0.0006 & 0.31 & 0.5952 \\
\hline$x_{1} x_{3}$ & 1 & 0.0042 & 0.0042 & 2.09 & 0.1912 \\
\hline$x_{2} x_{3}$ & 1 & 0.0306 & 0.0306 & 15.17 & 0.0059 \\
\hline$X_{1}^{2}$ & 1 & 0.1047 & 0.1047 & 51.91 & 0.0002 \\
\hline$x_{2}^{2}$ & 1 & 0.0254 & 0.0254 & 12.61 & 0.0093 \\
\hline$x_{3}^{2}$ & 1 & 0.0362 & 0.0362 & 17.94 & 0.0039 \\
\hline Lack of fit & 3 & 0.0087 & 0.0029 & 3.88 & 0.1117 \\
\hline
\end{tabular}

significant at the level of $p<0.05$. F-values for lack-offit were 3.43 and 3.88 for rutin and quercetin, respectively. The lack-of-fit was not significant $(p>0.05)$. The $\mathrm{R}^{2}$ of the models for rutin and quercetin content were 0.9572 and 0.9528 , respectively. Moreover, the coefficients of variation (CV) were 1.43 and 1.57 for rutin and quercetin, respectively. Experimental results were predicted with good accuracy when a low coefficient of variation $(\mathrm{CV})$ was obtained.

Three-dimensional plots was used to better understanding the relationship between independent and dependent variables, then the following quadratic polynomial model equations $(2,3)$ were assigned to generate the contour plots:

$$
\begin{aligned}
\text { Rutin }=2.89 & +0.0325^{*} X_{1}+0.02375^{*} X_{2} \\
& +0.06875^{*} X_{3}-0.0025^{*} X_{1} X_{2}+0.0025 \\
& * X_{1} X_{3}+0.015^{*} X_{2} X_{3}-0.1525^{*} X_{1}^{2}-0.09 \\
& * X_{2}^{2}-0.095^{*} X_{3}^{2}
\end{aligned}
$$


Table 3 Analysis of variance results for the regression (pumpkin)

\begin{tabular}{|c|c|c|c|c|c|}
\hline Source & $\begin{array}{l}\text { Degree of } \\
\text { freedom }\end{array}$ & $\begin{array}{l}\text { Sum of } \\
\text { square }\end{array}$ & $\begin{array}{l}\text { Mean } \\
\text { square }\end{array}$ & F-value & $p$-value \\
\hline \multicolumn{6}{|l|}{ Ellagic acid } \\
\hline Model & 9 & 0.1341 & 0.0150 & 14.30 & 0.0010 \\
\hline$X_{1}$ & 1 & 0.0171 & 0.0171 & 16.42 & 0.0049 \\
\hline$x_{2}$ & 1 & 0.0040 & 0.0040 & 3.89 & 0.0893 \\
\hline$x_{3}$ & 1 & 0.0153 & 0.0153 & 14.69 & 0.0064 \\
\hline$x_{1} x_{2}$ & 1 & 0.0144 & 0.0144 & 13.82 & 0.0075 \\
\hline$x_{1} x_{3}$ & 1 & 0.0072 & 0.0072 & 6.93 & 0.0338 \\
\hline$x_{2} x_{3}$ & 1 & 0.0025 & 0.0025 & 2.40 & 0.1653 \\
\hline$X_{1}^{2}$ & 1 & 0.0516 & 0.0516 & 49.56 & 0.0002 \\
\hline$X_{2}^{2}$ & 1 & 1.2894 & 1.2894 & 0.012 & 0.9146 \\
\hline$X_{3}^{2}$ & 1 & 0.0182 & 0.0182 & 17.47 & 0.0041 \\
\hline Lack of fit & 3 & 0.0025 & 0.00085 & 0.7274 & 0.586 \\
\hline \multicolumn{6}{|l|}{ Myricetin } \\
\hline Model & 9 & 0.1277 & 0.0141 & 15.30 & 0.0008 \\
\hline$X_{1}$ & 1 & 0.0171 & 0.0171 & 18.44 & 0.0036 \\
\hline$x_{2}$ & 1 & 0.00405 & 0.00405 & 4.36 & 0.0751 \\
\hline$x_{3}$ & 1 & 0.01531 & 0.01531 & 16.50 & 0.0048 \\
\hline$x_{1} x_{2}$ & 1 & 0.0144 & 0.0144 & 15.52 & 0.0056 \\
\hline$x_{1} x_{3}$ & 1 & 0.0072 & 0.0072 & 7.79 & 0.0269 \\
\hline$x_{2} x_{3}$ & 1 & 0.0025 & 0.0025 & 2.69 & 0.1447 \\
\hline$X_{1}^{2}$ & 1 & 0.0479 & 0.0479 & 51.71 & 0.0002 \\
\hline$x_{2}^{2}$ & 1 & 0.0001 & 0.0001 & 0.15 & 0.7100 \\
\hline$X_{3}^{2}$ & 1 & 0.0160 & 0.0160 & 17.30 & 0.0042 \\
\hline Lack of fit & 3 & 0.0025 & 0.00085 & 0.88 & 0.5244 \\
\hline
\end{tabular}

$$
\begin{aligned}
\text { Quercetin }=2.77 & +0.0325^{*} X_{1}+0.02125^{*} X_{2} \\
& +0.06625^{*} X_{3}-0.0024^{*} X_{1} X_{2} \\
& +0.0025^{*} X_{1} X_{3}+0.015^{*} X_{2} X_{3} \\
& -0.1525^{*} X_{1}^{2}-0.09^{*} X_{2}^{2}-0.095^{*} X_{3}^{2}
\end{aligned}
$$

The effects of parameter variables (ultrasonic temperature, power, and extraction time) and their interactions on rutin and quercetin contents in peach were studied. The third variable was assigned to be constant at the intermediate setting while surface plots of threedimensions were shown by two independent variables. As shown in Fig. 3a, with increase extraction temperature from $30{ }^{\circ} \mathrm{C}$ to $41.08{ }^{\circ} \mathrm{C}$, the extraction amount of rutin quickly increased and reached the maximum value at 0 level of extraction time in the fixed extraction power of $53.24 \%$. However, with the increase of extraction temperature from $41.08{ }^{\circ} \mathrm{C}$ to $50{ }^{\circ} \mathrm{C}$, the amount of rutin quickly decreased. This result confirmed that higher temperature can enhance the solubility of the solute thereby increases the yield of flavonoids. But, at the same time, increasing temperature can reduce the solvent density and consequently decreases the yield of total flavonoids. Therefore, the increase in temperature could have either a positive or a negative effect [36]. This finding was in agreement with Zhong [37] who reported that the thermal degradation of flavonoids and the decrease of number of acoustic cavitation bubbles were caused to decrease the amount of rutin. Figure $3 b$ shows the effect of the interaction of extraction temperature and extraction time on the rutin content at a fixed extraction power of 0 level. Maximum rutin content was obtained at $41.08^{\circ} \mathrm{C}$ and then decreased slightly by increasing extraction temperature to $50{ }^{\circ} \mathrm{C}$ in the fixed extraction time of $23.77 \mathrm{~min}$. Figure 3c shows the effect of the interaction of extraction power and extraction time on the rutin content at a fixed extraction temperature of 0 level. Maximum rutin content was obtained at the highest extraction time in the fixed extraction power of $53.24 \%$. Moreover, the results found that extraction time $\left(\mathrm{X}_{3}\right)$ was the most significant factor affecting the responses at the level of $p<0.01$. Figure 4 a shows the effect of the interaction of extraction temperature and extraction power on the quercetin content at a fixed extraction time of 0 level.

Maximum quercetin content was obtained at the lowest extraction temperature and reached the maximum value at $41.11{ }^{\circ} \mathrm{C}$ of extraction temperature in the fixed extraction power of $52.92 \%$. Figure $4 \mathrm{~b}$ shows the effect of the interaction of extraction temperature and extraction time on the quercetin content at a fixed extraction power of 0 level. Maximum quercetin content was also obtained at the lowest extraction temperature and then decreased slightly by increasing extraction temperature to $50{ }^{\circ} \mathrm{C}$ in the fixed extraction time of $23.61 \mathrm{~min}$. The decrease may be explained by oxidation and degradation of flavonoids due to sonication process with both highest extraction temperature and longest extraction time [38]. Figure $4 c$ shows the effect of the interaction of extraction power and extraction time on the quercetin content at a fixed extraction temperature of 0 level. Maximum quercetin content was obtained at $52.92 \%$ of extraction power in the fixed extraction time of $23.61 \mathrm{~min}$.

\section{Effect of ultrasonic parameters on ellagic acid and myricetin} contents of pumpkin and analysis of response surfaces

Table 3 lists the analysis of variance of the fitted quadratic polynomial model for ellagic acid and myricetin contents in pumpkin extracts. For ellagic acid content $(\mu \mathrm{g} / \mathrm{g}$ of dry matter), the linear parameters (temp, time) were significant; interaction parameter (temp* power) and (temp*time) were significant $(p<0.05)$ while all quadratic parameters were significant at the level of $p<0.05$. In myricetin content ( $\mu \mathrm{g} / \mathrm{g}$ of dry matter), the linear parameters (temp, time) were significant; the interaction parameters 

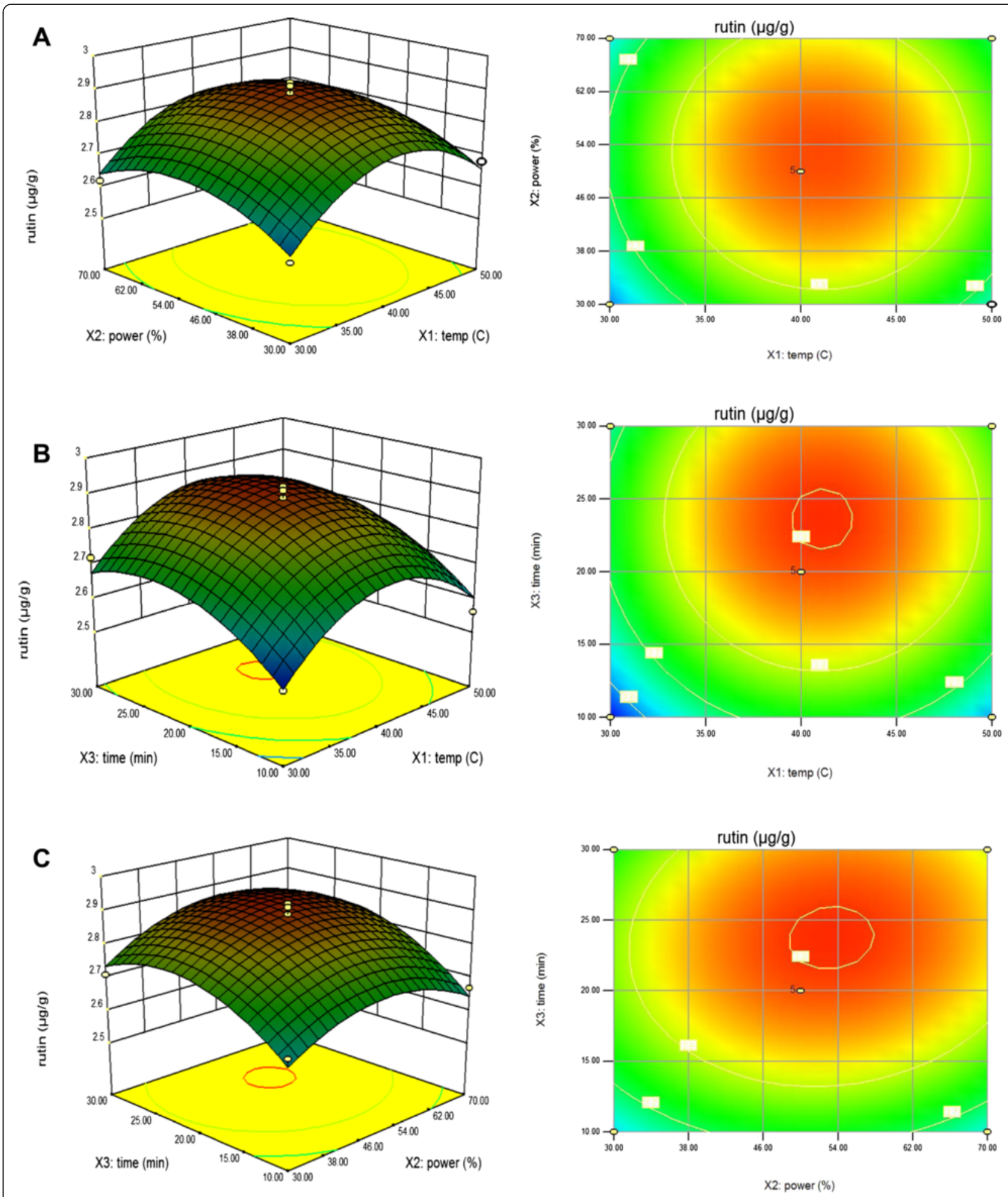

Fig. 3 Response surface model plot showing the effects of of independent variables on rutin content. Panel (a) temperature and power. Panel (b) temperature and time. Panel (c) power and time 

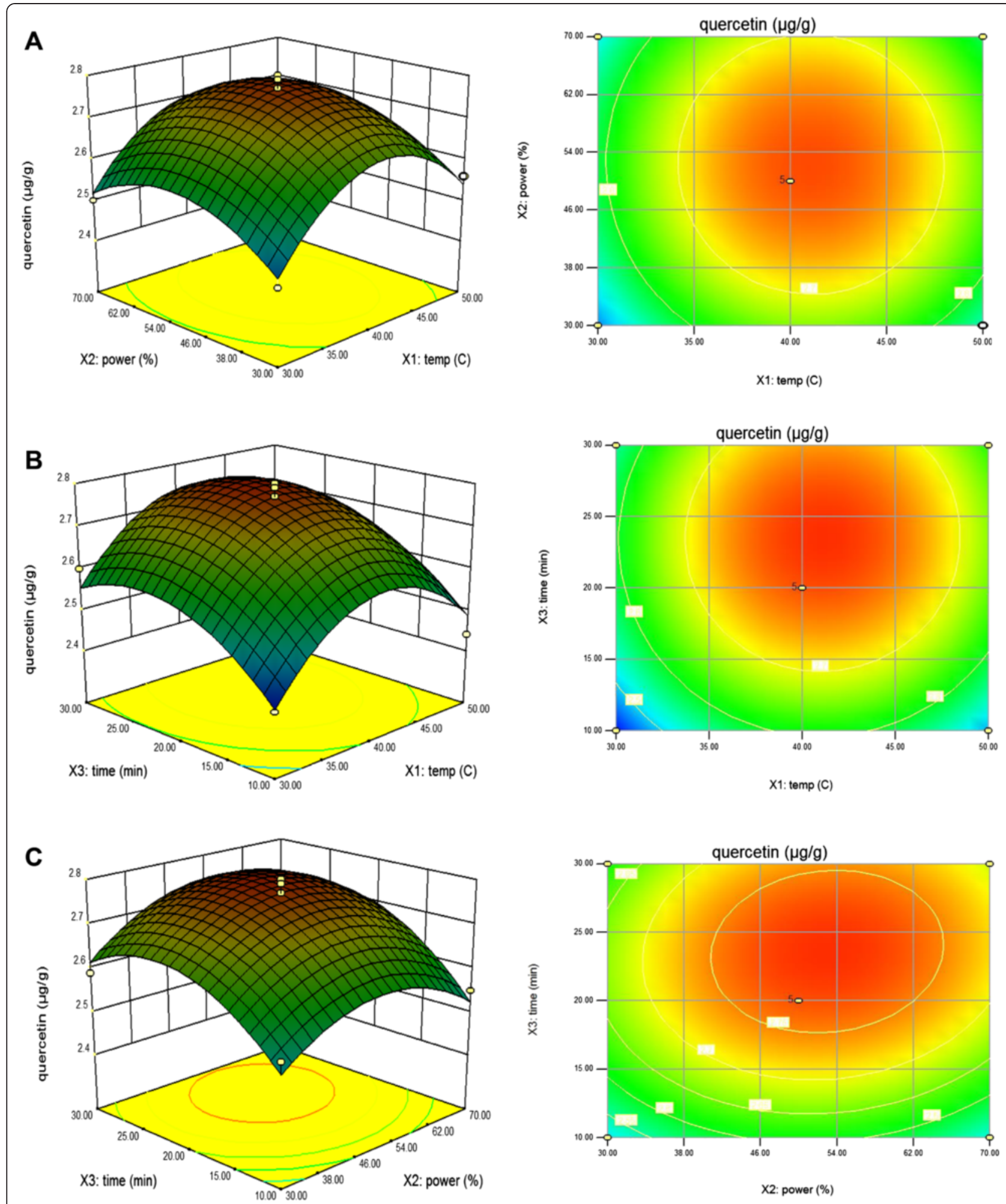

Fig. 4 Response surface model plot showing the effects of of independent variables on quercetin content. Panel (a) temperature and power. Panel (b) temperature and time. Panel (c) power and time 
(temp*power, temp*time) were significant at the level of $p<0.001$ and (power" time) was not significant $(p>0.05)$ while quadratic parameters $\left(\mathrm{X}_{1}^{2}, \mathrm{X}_{3}^{2}\right)$ were significant at the level of $p<0.05$. The F-value of 14.30, 15.30 of ellagic acid and myricetin contents respectively implied the model was significant. The lack-of-fit F-value of 0.7274 and 0.88 of ellagic acid and myricetin contents respectively reflects that the lack-of-fit was not significant. The $\mathrm{R}^{2}$ of the models for ellagic acid and myricetin contents were 0.9484 and 0.9516 , respectively. Moreover, the coefficients of variation $(\mathrm{CV})$ were 1.10 and 1.06 for ellagic acid and myricetin contents, respectively.

Response surface models were used according to the following quadratic polynomial model equations $(4,5)$ in order to study the effects of parameter variables (ultrasonic temperature, power, and extraction time) and their interactions on ellagic acid and myricetin contents of pumpkin extracts. The third variable was assigned to be constant at the intermediate point while surface plots of three-dimensions were made by two independent variables.

$$
\begin{aligned}
\text { Ellagic acid }=3 & +0.046^{*} X_{1}-0.0225^{*} X_{2}-0.0441 \\
& * X_{3}+0.06^{*} X_{1} X_{2}+0.044^{*} X_{1} X_{3} \\
& -0.025^{*} X_{2} X_{3}-0.112^{*} X_{1}^{2}+0.00174 \\
& * X_{2}^{2}-0.066^{*} X_{3}^{2}
\end{aligned}
$$

$$
\begin{aligned}
\text { Myricetin }=2.96 & +0.046^{*} X_{1}-0.022 * X_{2}-0.0445 \\
& * X_{3}+0.060^{*} X_{1} X_{2}+0.043^{*} X_{1} X_{3} \\
& -0.025^{*} X_{2} X_{3}-0.11^{*} X_{1}^{2}+0.00574 \\
& * X_{2}^{2}-0.062 * X_{3}^{2}
\end{aligned}
$$

As shown in Fig. 5a, when extraction time was fixed at 0 level, ellagic acid contents were improved while the extraction temperature increased from $30{ }^{\circ} \mathrm{C}$ to $38.81{ }^{\circ} \mathrm{C}$, and reached the maximum value in the fixed extraction power of $33.23 \%$, and then the amount of ellagic acid contents decreased when the extraction temperature reached $50{ }^{\circ} \mathrm{C}$ due to the degradation of ellagic acid. The extraction amount of ellagic acid was affected by different ultrasonic extraction temperatures and ultrasonic extraction times as seen in Fig. 5b, when extraction power was fixed at 0 levels. It can be seen that the extraction amount of ellagic acid increased with the increasing ultrasonic extraction time and reached the maximum value at $18.51 \mathrm{~min}$ of extraction time. This finding was not in agreement with Zhang et al. [39] who found that the maximum value of ellagic acid from infructescence of $P$. latycarya strobilacea $L$. was at 40 min of extraction time. However, this result was concurred with Novak et al. [40] and Rostagno et al. [41] who confirmed that exposure to ultrasonic treatment for long time may cause loss to polyphenolic compounds due to denaturation, so it is very important to consider sonication time while processing. Figure $5 \mathrm{c}$ shows the effect of the interaction of extraction power and extraction time on the ellagic acid content at a fixed extraction temperature of 0 level. Maximum ellagic acid content was obtained at $18.51 \mathrm{~min}$ of extraction time in the fixed extraction power of $33.23 \%$. Moreover, the results were found that extraction temperature $\left(\mathrm{X}_{1}\right)$ and extraction time $\left(\mathrm{X}_{3}\right)$ were the most significant factor affecting the responses at the level of $p<0.01$.

Figure 6a shows the effect of the interaction of extraction temperature and extraction power on the myricetin contents at a fixed extraction time of 0 level. Maximum myricetin content was obtained at the highest extraction temperature and reached the maximum value at $38.98{ }^{\circ} \mathrm{C}$ of extraction temperature in the fixed extraction power of $33.79 \%$. Figure $6 \mathrm{~b}$ shows the effect of the interaction of extraction temperature and extraction time on the myricetin content at a fixed extraction power of 0 level. Maximum myricetin content was also obtained by increasing extraction temperature to $40{ }^{\circ} \mathrm{C}$ in the fixed extraction time of $18.13 \mathrm{~min}$. These results were in agreement with Shakthi Deve et al. [42] who found that the longest extraction time for flavonoids may result in loss to the polyphenols due to oxidation process. The oxidized products can convert to insoluble form compounds thereby diffusion of the polyphenols will be inhibited. Figure $6 \mathrm{c}$ shows the effect of the interaction of extraction power and extraction time on the myricetin content at a fixed extraction temperature of 0 level. Maximum myricetin content was obtained at the highest extraction power and reached the maximum value at $33.79 \%$ of extraction power in the fixed extraction time of $18.13 \mathrm{~min}$. Moreover, the results found that extraction temperature $\left(\mathrm{X}_{1}\right)$ and extraction time $\left(\mathrm{X}_{3}\right)$ were the most significant factor affecting the responses at the level of $p<0.01$.

\section{Optimization and verification of the model for ultrasonic parameters}

In order to verify the rutin and quercetin contents simultaneously from peach extracts, there was one optimal extraction conditions, which was established to get the highest values: modifying the extraction temperature of $41.08{ }^{\circ} \mathrm{C}$ to $40{ }^{\circ} \mathrm{C}$, extraction power of $53.09 \%$ to $50 \%$, and extraction time of $23.68 \mathrm{~min}$ to $24 \mathrm{~min}$. The results are shown in Table 4 and the amounts of rutin and quercetin contents respectively under the optimal predicted conditions and experimental conditions. There was significant difference $(p>0.05)$ between the experimental and predicted values. Thus, this modification was not appropriate to assign in order to optimize the process of rutin and quercetin contents from peach. It seems that it 

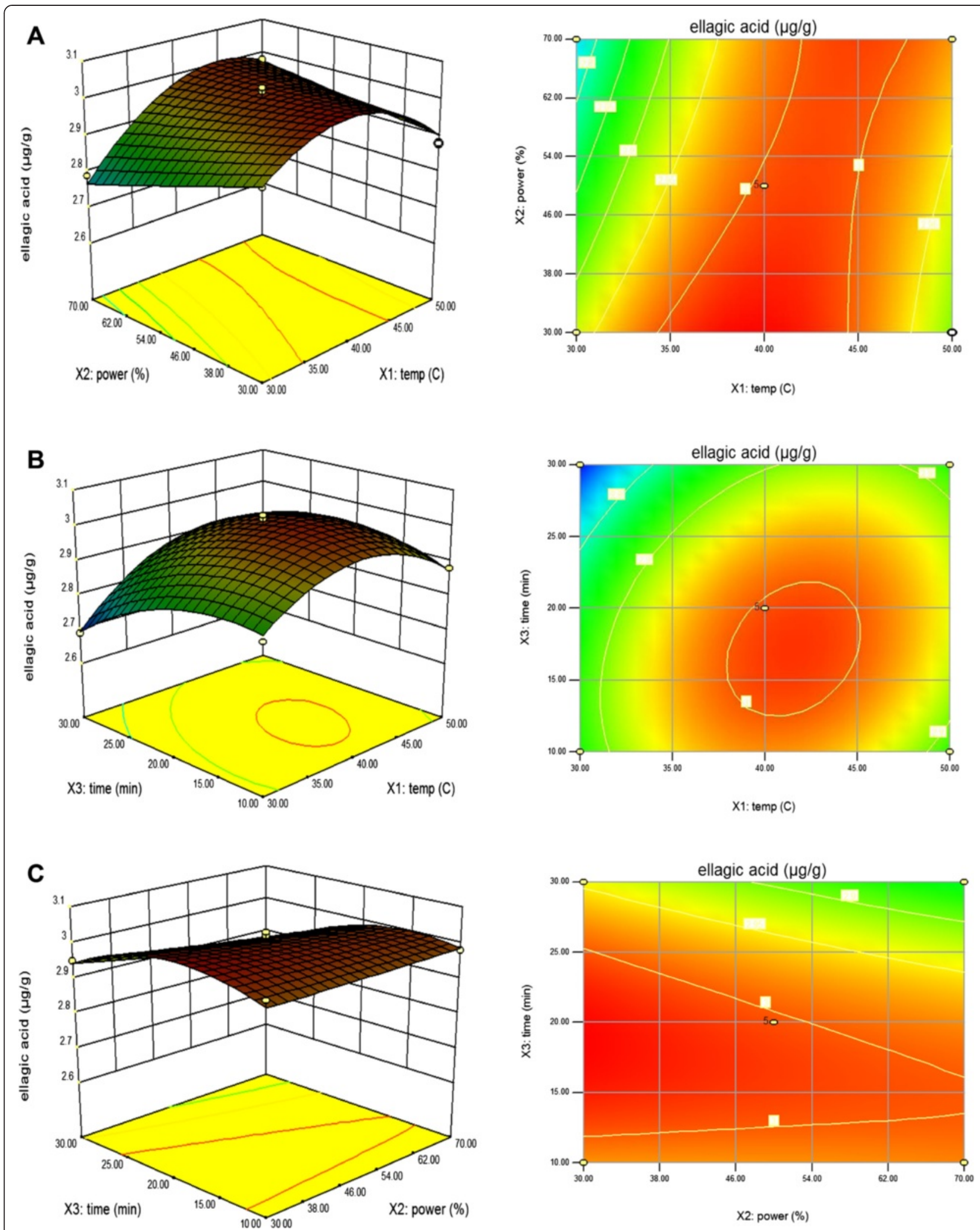

Fig. 5 Response surface model plot showing the effects of of independent variables on ellagic acid content. Panel (a) temperature and power. Panel (b) temperature and time. Panel (c) power and time 

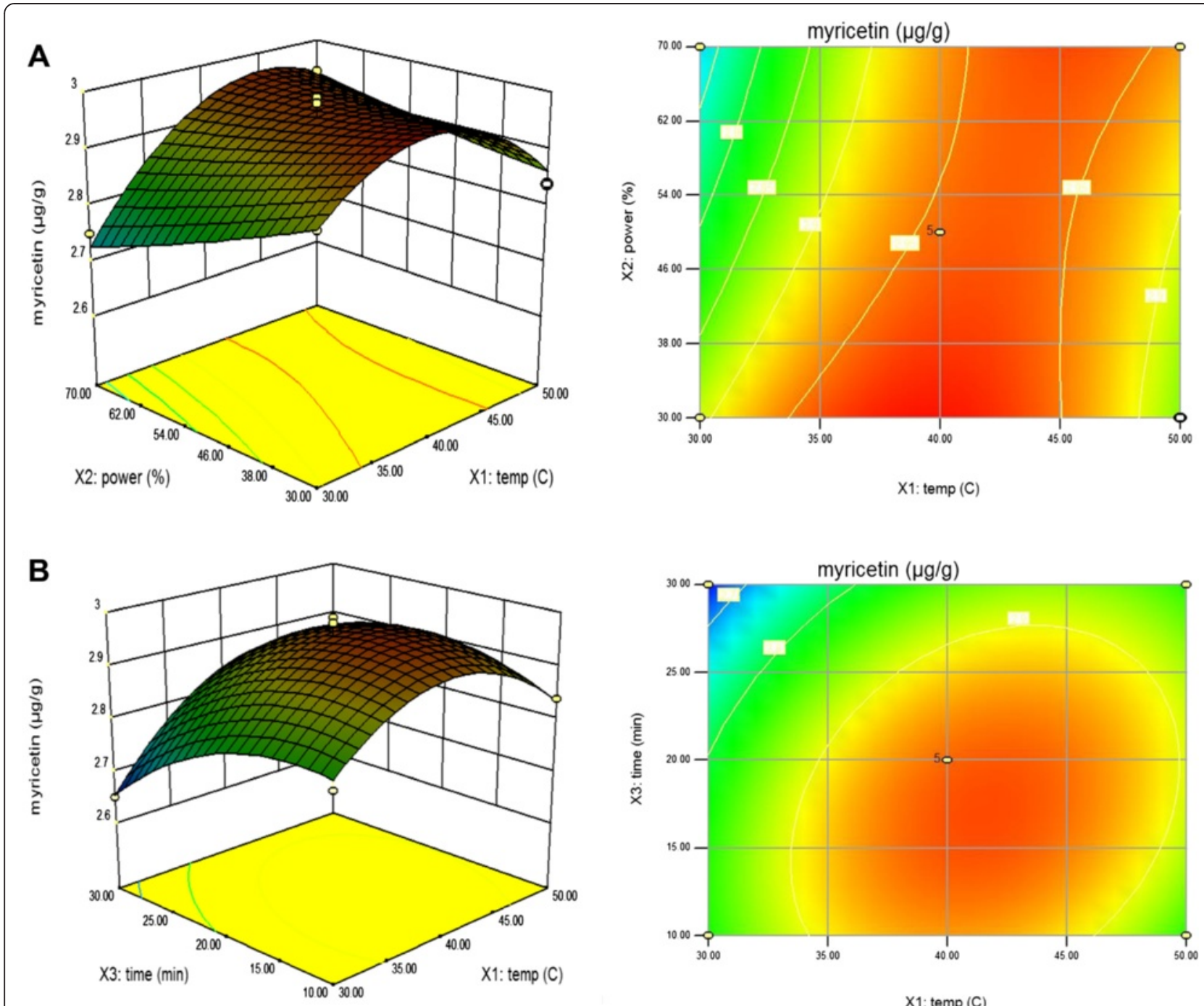

X1: temp (C)
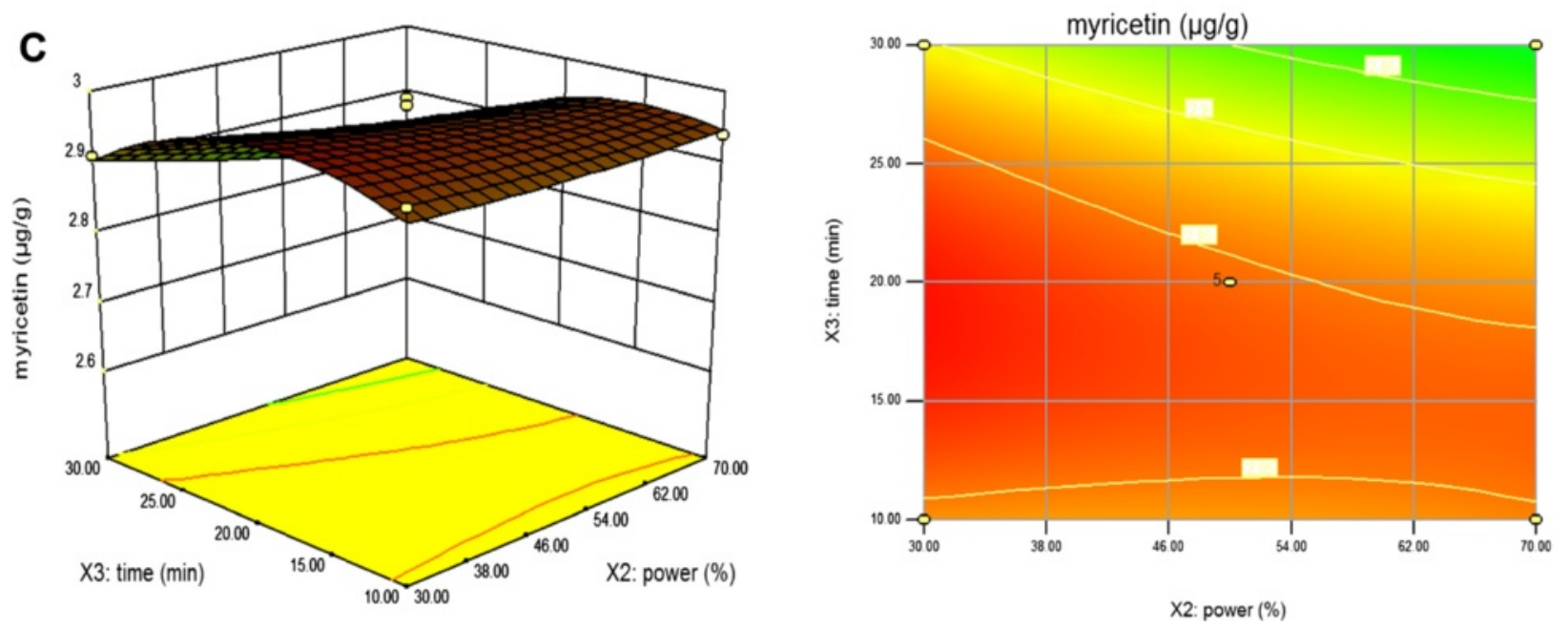

Fig. 6 Response surface model plot showing the effects of of independent variables on myricetin content. Panel (a) temperature and power. Panel (b) temperature and time. Panel (c) power and time 
Table 4 Predicted and actual experimental values of rutin and quercetin $(\mu \mathrm{g} / \mathrm{g})$ from peach extracts; and ellagic acid and myricetin $(\mu \mathrm{g} / \mathrm{g})$ from pumpkin under the optimal extraction conditions

\begin{tabular}{|c|c|c|c|c|c|c|}
\hline \multirow[t]{2}{*}{ Selected plants } & \multirow[t]{2}{*}{ Isolated compounds } & \multicolumn{3}{|c|}{ Extraction variables } & \multirow[t]{2}{*}{ Predicated values } & \multirow[t]{2}{*}{ Experimental values } \\
\hline & & $\mathrm{X}_{1}\left({ }^{\circ} \mathrm{C}\right)$ & $x_{2}(\%)$ & $x_{3}(\min )$ & & \\
\hline \multirow[t]{2}{*}{ Peach } & $\overline{R-P}$ & 41.08 & 53.09 & 23.68 & $2.906 \pm 0.039$ & $2.816 \pm 0.0305$ \\
\hline & Q-P & & & & $2.785 \pm 0.040$ & $2.733 \pm 0.0208$ \\
\hline \multirow[t]{2}{*}{ Pumpkin } & E-PP & 38.99 & 33.12 & 18.15 & $3.030 \pm 0.032$ & $2.96 \pm 0.05$ \\
\hline & M-PP & & & & $2.986 \pm 0.030$ & $2.953 \pm 0.06$ \\
\hline
\end{tabular}

${ }^{\mathrm{a}}$ Mean \pm standard deviation $(n=3) .(R-P)=$ Rutin-peach; $(Q-P)=$ Quercetin-peach; $(E-P P)=$ ellagic acid-pumpkin; $(M-P P)=$ myricetin-pumpkin

was required to use the same optimized values for temperature, power, and time in order to get highest values for both rutin and quercetin contents.

In order to facilitate the extraction process for pumpkin extracts, the optimal condition was modified as follows: the extraction temperature of $38.99{ }^{\circ} \mathrm{C}$ to $40{ }^{\circ} \mathrm{C}$, and extraction power of $33.12 \%$ to $33 \%$, and extraction time of $18.15 \mathrm{~min}$ to $18 \mathrm{~min}$. The results are shown in Table 4 and the amounts of ellagic acid and myricetin contents respectively under the optimal predicted conditions and experimental conditions. There was no significant difference $(p>0.05)$ between the experimental and predicted values. Hence, the models can be used to optimize the process of ellagic acid and myricetin contents from pumpkin.

\section{MALDI identification}

Figure 7 shows the MALDI mass spectra obtained for TLC Spot Q-P (Fig. 7a) and TLC Spot R-P (Fig. 7c). Ion signals were observed at $\mathrm{m} / \mathrm{z} 302.7$ and 632.9. These ion signals were also observed in the MALDI mass spectra obtained from the certified quercetin (Q) (Fig. 7b) and rutin (R) (Fig. 7d) standards, respectively, and were assigned to the molecular radical cation $\left(\mathrm{M}^{+}\right)$of quercetin $(\mathrm{Q})$ and the sodiated cation $\left(\mathrm{M}+\mathrm{Na}^{+}\right)$of rutin $(\mathrm{R})$.

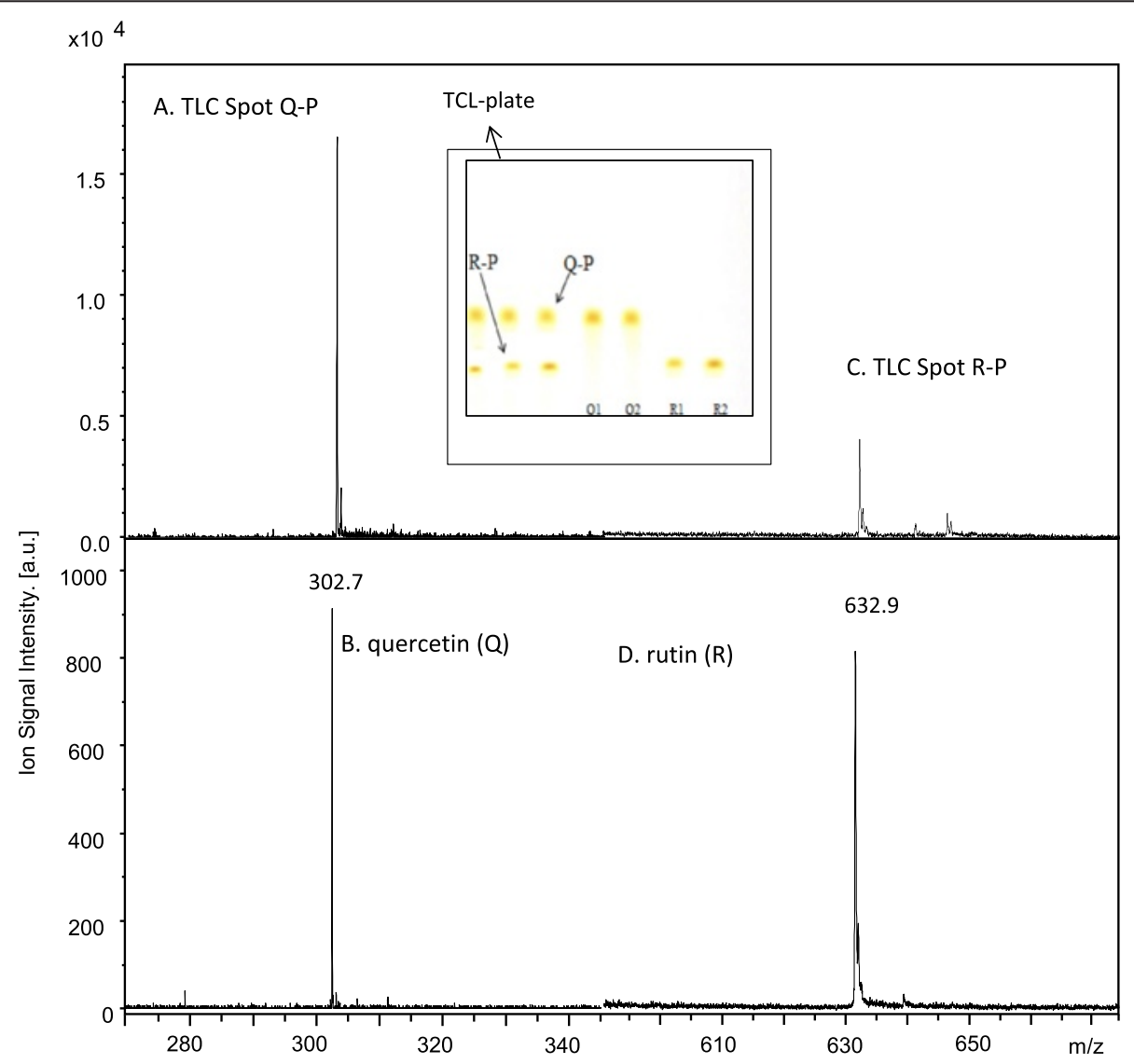

Fig. 7 Mass spectra of peach extract TLC spot Q-P (a) and TLC spot R-P(c) excised and compared to quercetin Q (b) and rutin R (d) standards 


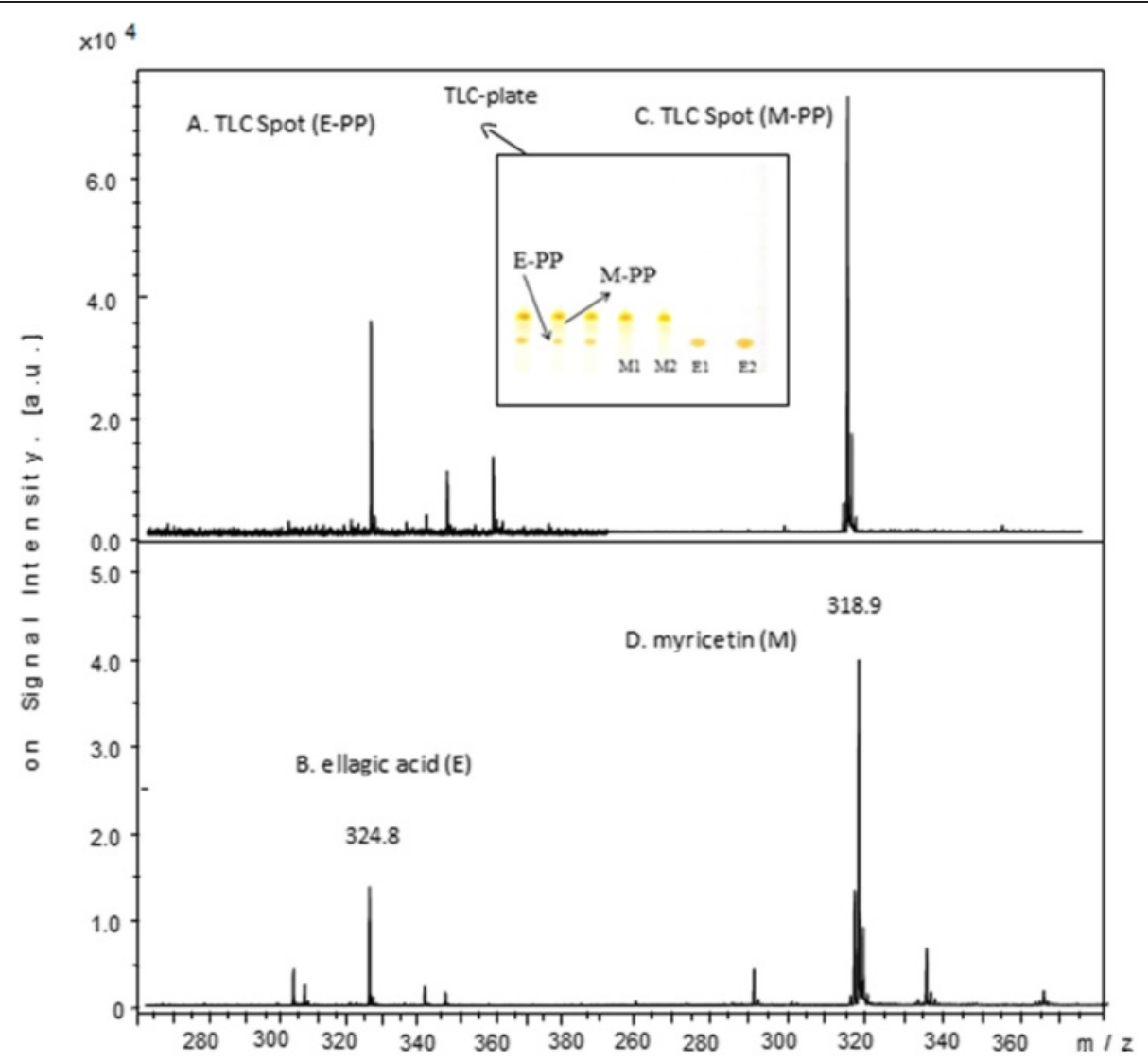

Fig. 8 Mass spectra of pumpkin extract TLC spot E-PP (a) and TLC spot M-PP (c) excised and compared to ellagic acid E (b) and myricetin M (d) standards

Figure 8 shows the LDI mass spectrum obtained for the TLC Spot E-PP (Fig. 8a) and the MALDI mass spectrum obtained for the TLC Spot M-PP (Fig. 8c). Ion signals were observed at $\mathrm{m} / z 324.8$ and 318.9 , respectively, and were assigned to the sodiated cation $\left(\mathrm{M}+\mathrm{Na}^{+}\right)$of ellagic acid $(\mathrm{E})$ and molecular radical cation $\left(\mathrm{M}^{+}\right)$of myricetin $(\mathrm{M})$.

\section{Conclusion}

The results of this study indicated that the ultrasonic treatments had the ability to enhance and increase the amount of polyphenol extraction yields from plants extracts (peach and pumpkin). TLC-densitometric method and BBD can be a very powerful technique in quantitative analysis of rutin and quercetin from peach extracts and ellagic acid and myricetin contents from pumpkin extracts. A high correlation of the quadratic polynomial mathematical model was gained and could be employed to optimize rutin and quercetin from peach extracts and ellagic acid and myricetin contents from pumpkin extracts by ultrasonic-assisted assay. The modified optimal extraction conditions for measuring rutin and quercetin simultaneously from peach extracts were as follows: extraction temperature of $41{ }^{\circ} \mathrm{C}$, extraction power of $53 \%$, and extraction time of $24 \mathrm{~min}$. Under these conditions, the experimental results of total rutin and quercetin contents were $2.816 \pm 0.0305 \mu \mathrm{g} / \mathrm{g}$ of dry matter and $2.733 \pm 0.0208 \mu \mathrm{g} / \mathrm{g}$ of dry matter respectively, which agreed closely with the predicted yield values. In contrast, the modified optimal extraction conditions for measuring ellagic acid and myricetin contents simultaneously from pumpkin extracts were as follows: extraction temperature of $40{ }^{\circ} \mathrm{C}$, extraction power of $33 \%$, and extraction time of $18 \mathrm{~min}$. Under these conditions, the experimental results of total ellagic acid and myricetin contents were $2.96 \pm 0.05 \mu \mathrm{g} / \mathrm{g}$ of dry matter and $2.953 \pm 0.06 \mu \mathrm{g} / \mathrm{g}$ of dry matter respectively, which agreed closely with the predicted yield values.

\section{Competing interests}

The authors declare that they have no competing interests.

\section{Authors' contributions}

AA, designed, carried out and wrote-up the research; MK, designed and carried out the MALDI analyses; DGW helped design and analyze experiments and coordination and helped draft the manuscript; DAL, supervised and helped design the research; and proofread the article. All authors read and approved the final manuscript. 


\section{Acknowledgement}

The authors like to thank the Higher Committee for Education Development in Iraq (HCED) for the financial support to achieve this work and Dr. Stuart Alan Walters of the Department of Plant, Soil and Agricultural Systems, College of Agricultural Sciences, Southern Illinois University, USA supervised the production and harvest of the peach and pumpkin used in this study.

\section{Author details}

${ }^{1}$ Department of Plant, Soil and Agricultural Systems, Southern Illinois University, Carbondale, IL 62901, USA. ${ }^{2}$ Department of Food Science, College of Agriculture, University of Basrah, Basrah 61004, Iraq. ${ }^{3}$ SIUC Mass Spectrometry Facility, Department of Chemistry and Biochemistry, SIUC, Carbondale, IL 62901, USA.

Received: 4 February 2015 Accepted: 10 June 2015 Published online: 20 June 2015

\section{References}

1. Brusotti G, Cesari I, Dentamaro A, Caccialanza G, Massolini G. Isolation and characterization of bioactive compounds from plant resources: the role of analysis in the ethnopharmacological approach. J Pharm Biomed Anal. 2014;87:218-28.

2. Sarala V, Radhakrishnan M, Balagurunathan R. Inhibitory activity of terpenoid from the medicinal plant Andrographis paniculata against biofouling bacteria. Int J Chem Tech Res. 2011;3:1225-31.

3. Nassr-Allah AA, Aboul-Enein AM, Aboul-Enein KM, Lightfoot DA, Cocchetto A, El-Shemy HA. Anti-cancer and anti-oxidant activity of some Egyptian medicinal plants. J Med Plants Res. 2009;3(3):799-808.

4. El-Shemy HA, Aboul-Enein KM, Cocchetto A, Lightfoot DA. Predicting which natural products of plants may kill leukaemia cells (In-silico selection of anti-leukaemia natural products). J Evid Based Complementary Altern Med. 2013;2:1-10

5. Rauha JP, Remes $\mathrm{S}$, Heinonen $M$, Hopia A, Kähkönen $M$, Kujala $T$, et al. Antimicrobial effects of Finnish plant extracts containing flavonoids and other phenolic compounds. Int J Food Microbiol. 2000;56(1):3-12.

6. Ghosh P, Katiyar A. Densitometric HPTLC analysis of juglone, quercetin, myricetin, rutin, caffeic acid, and gallic acid in Juglans regia L. JPC J Planar Chromatogr - Mod. 2012;25(5):420-5.

7. Bros I, Soran ML, Briciu RD, Cobzac SC. HPTLC quantification of some flavonoids in extracts of Satureja hortensis $L$. obtained by use of different techniques. JPC J Planar Chromatogr - Mod. 2009;22(1):25-8.

8. He X, Lin L, Lian L. Analysis of flavonoids from red clover by liquid chromatography-electrospray mass spectrometry. J Chromatogr A. 1996;755(1):127-32.

9. Mot AC, Soponar F, Sarbu C. Multivariate analysis of reflectance spectra from propolis: geographical variation in Romanian samples. Talanta. 2010;81(3):1010-5

10. Nascu-Briciu RD, Cobzac SC, Baciu S. Optimum ultrasound assisted extraction conditions of some flavonoids from green tea leaves. Control quality of green tea product by TLC fingerprinting. Anal Lett. 2011:44(18):2865-75.

11. Repolles C, Herrero-Martinez JM, Rafols C. Analysis of prominent flavonoid aglycones by high-performance liquid chromatography using a monolithic type column. J Chromatogr A. 2006;1131(1-2):51-7.

12. Al-Temimi A, Choudahry R. Determination of antioxidant activity in different kinds of plants in vivo and in vitro by using diverse technical methods. J Nutr Food Sci. 2013;3(1):1-6.

13. Herrera MC, de Castro MDL. Ultrasound-assisted extraction of phenolic compounds from strawberries prior to liquid chromatographic separation and photodiode array ultraviolet detection. J Chromatogr A. 2005;1 100(1):1-7.

14. Bajer T, Adam M, Galla L, Ventura K. Comparison of various extraction techniques for isolation and determination of isoflavonoids in plants. J Sep Sci. 2007;30(1):122-7.

15. Chemat F, Zill-e-Huma, Khan MK. Applications of ultrasound in food technology: processing, preservation and extraction. Ultrason Sonochem. 2011;18(4):813-35.

16. Pratt $D E$, Watts $B M$. The antioxidant activity of vegetable extracts I. flavone aglycones. J Food Sci. 1964;29:27-33.

17. Zeb A, Murkovic M. Thin-layer chromatographic analysis of carotenoids in plant and animal samples. JPC J Planar Chromatogr - Mod TLC. 2010;23:94-103.
18. Fuchs B, Suss R, Teuber K, Eibisch M, Schiller J. Lipid analysis by thin-layer chromatography - a review of the current state. J Chromatogr A. 2011;1218(19):2754-74

19. James J, Dubery I. Identification and quantification of triterpenoid centelloids in Centella asiatica (L.) urban by densitometric TLC. JPC - J Planar Chromatogr - Mod TLC. 2011;24(1):82-7.

20. Chaowuttikul C, Thitikornpong W, Palanuvej C. Quantitative determination of usnic acid content in usnea siamensis by TLC- densitometry and TLC image analysis. Res J Pharm Biol Chem Sci. 2014;5(1):118-25.

21. Starek M, Krzek J. TLC chromatographic-densitometric assay of ibuprofen and its impurities. J Chromatogr Sci. 2010;48(10):825-9.

22. Nikolova M, Berkov S, Ivancheva S. A rapid TLC method for analysis of external flavonoid aglycons in plant exudates. Acta Chromatogr. 2004;14:110-4.

23. Ciesla L, Staszek D, Kowalska T, Waksmundzka-Hajnos M. The use of TLC-DPPH test with image processing to study direct antioxidant activity of phenolic acid fractions of selected Lamiaceae family species. J AOAC Int. 2013;96(6):1228-32.

24. Proestos C, Boziaris IS, Nychas GJE, Komaitis M. Analysis of flavonoids and phenolic acids in Greek aromatic plants: Investigation of their antioxidant capacity and antimicrobial activity. Food Chem. 2006;95(4):664-71.

25. Khoddami A, Wilkes MA, Roberts TH. Techniques for analysis of plant phenolic compounds. Molecules. 2013;18(2):2328-75.

26. Bezerra MA, Santelli RE, Oliveira EP, Villar LS, Escaleira LA. Response surface methodology (RSM) as a tool for optimization in analytical chemistry. Talanta. 2008;76(5):965-77.

27. Altemimi A, Choudhary R, Watson DG, Lightfoot DA. Effects of ultrasonic treatments on the polyphenol and antioxidant content of spinach extracts. Ultrason Sonochem. 2015;24:247-55.

28. Altemimi A, Lightfoot DA, Kinsel M, Watson DG. Employing response surface methodology for the optimization of ultrasound assisted extraction of lutein and $\beta$-carotene from spinach. Molecules. 2015:20:6611-25.

29. Kikuchi T, Uchida T. Calorimetric method for measuring high ultrasonic power using water as a heating material. J Phys Conf Ser. 2011;279:012012.

30. Harbone J. Phytochemical method. 2nd ed. New York: Chapman Hall; 1986

31. Buer CS, Djordjevic MA. Architectural phenotypes in the transparent testa mutants of Arabidopsis thaliana. J Exp Bot. 2009;60(3):751-63.

32. Dmitrienko SG, Kudrinskaya VA, Apyari W. Methods of extraction, preconcentration, and determination of quercetin. J Anal Chem. 2012;67(4):299-311.

33. Delgado-Vargas F, Jimenez A, Paredes-Lopez O. Natural pigments: carotenoids, anthocyanins, and betalains-characteristics, biosynthesis, processing, and stability. Crit Rev Food Sci Nutr. 2000:40(3):173-289.

34. Lee LS, Lee N, Kim YH, Lee CH, Hong SP, Jeon YW, et al. Optimization of ultrasonic extraction of phenolic antioxidants from green tea using response surface methodology. Molecules. 2013;18(11):13530-45.

35. Trinh TK, Kang LS. Application of response surface method as an experimental design to optimize coagulation test. Environ Eng Res. 2010;15(2):63-70.

36. Li W, Liu ZB, Wang Z, Chen L, Sun YS, Hou JG, et al. Application of accelerated solvent extraction to the investigation of saikosaponins from the roots of Bupleurum falcatum. J Sep Sci. 2010;33:1870-6.

37. Zhong Z. Optimization of ultrasound-assissted extraction conditions of flavonoids from Tartary Buckwheat. J Pharm Sci Innovation. 2012;1 (6):39-43.

38. Karabegovic I, Nikolova M, Velickovic D, Stojicevic S, Veljkovic V, Lazic M. Comparison of antioxidant and antimicrobial activities of methanolic extracts of the Artemisia sp. Recovered by different extraction techniques. Chinese J Chem Eng. 2011;19(3):504-11.

39. Zhang LL, Xu M, Wang YM, Wu DM, Chen JH. Optimizing ultrasonic ellagic acid extraction conditions from infructescence of Platycarya strobilaced using response surface methodology. Molecules. 2010;15(11):7923-32.

40. Novak I, Janeiro P, Seruga M, Oliveira-Brett AM. Ultrasound extracted flavonoids from four varieties of Portuguese red grape skins determined by reverse-phase high-performance liquid chromatography with electrochemical detection. Anal Chim Acta. 2008;630(2):107-15.

41. Rostagno MA, Palma M, Barroso CG. Ultrasound-assisted extraction of isoflavones from soy beverages blended with fruit juices. Anal Chim Acta. 2007;597(2):265-72.

42. Shakthi Deve A, Sathish Kumar T, Kumaresan K, Rapheal VS. Extraction process optimization of polyphenols from Indian Citrus sinensis-as novel antiglycative agents in the management of diabetes mellitus. J Diabetes Metab Disord. 2014;13(1):1-10. 